\title{
Determinants of postnatal checkup for newborns in Ethiopia: Further analysis of 2016 Ethiopia demographic and health
}

\section{survey}

\author{
Abdu Seid $^{1 *}$ (1) and Mohammed Ahmed ${ }^{2}$
}

\begin{abstract}
Background: The absence of suitable care during the postpartum period might result in substantial ill-health and even the demise of newborns. So, identifying and intervening thus factors increase postnatal newborn care utilization thereby reducing neonatal mortality. Therefore, this study aimed to ascertain the determinants of the postnatal checkup of a newborn in Ethiopia.

Method: A cross-sectional study was accompanied using the 2016 Ethiopia Demographic and Health Survey (EDHS) data set. The samples were designated by employing a two-stage stratified cluster sampling technique. All statistical analysis were weighted in order to take into consideration complex survey design. Bivariate and multivariate logistic regression analysis was also carried out to examine the association between use of postnatal care of newborn and selected independent variables. Adjusted odds ratios (AOR) were used to state a statistically significant suggestion.

Result: A total of 7091 samples of the reproductive age of newborn mothers were included and analyzed. According to multivariate analysis, the odds of postnatal checkups of the newborn were 2.45 times higher among mothers who had 1-3 ANC visits and 3.42 times higher among mothers who had four and above visits than mother who did not have ANC visit. The odds of postnatal checkups of the newborn were 1.4 times higher among mothers who had access to media compared to their counterparts. Likewise, the odds of postnatal checkups of the newborn were 1.67 times higher among mothers who had delivered in a health facility than who delivered at home.

Conclusions: This study revealed that accessed media, being rich or middle in the wealth index category, having ANC visits, and institutional delivery was positively associated with the utilization of postnatal care checkup of the newborn. Therefore, information education and communication programs should perform a critical role in inspiring mother to take their newborns for postnatal checkup after birth.
\end{abstract}

Keywords: Postnatal checkup, Newborn, Ethiopia

* Correspondence: abdus3536@gmail.com

'Department of Midwifery, College of Health Science, Woldia University, Woldia, Ethiopia

Full list of author information is available at the end of the article

(c) The Author(s). 2020 Open Access This article is licensed under a Creative Commons Attribution 4.0 International License, which permits use, sharing, adaptation, distribution and reproduction in any medium or format, as long as you give appropriate credit to the original author(s) and the source, provide a link to the Creative Commons licence, and indicate if changes were made. The images or other third party material in this article are included in the article's Creative Commons licence, unless indicated otherwise in a credit line to the material. If material is not included in the article's Creative Commons licence and your intended use is not permitted by statutory regulation or exceeds the permitted use, you will need to obtain permission directly from the copyright holder. To view a copy of this licence, visit http://creativecommons.org/licenses/by/4.0/. The Creative Commons Public Domain Dedication waiver (http://creativecommons.org/publicdomain/zero/1.0/) applies to the data made available in this article, unless otherwise stated in a credit line to the data. 


\section{Background}

According to WHO and UNICEF recommendations, women who delivered in health institutions and their babies should be evaluated for problems immediately within 24 hours and should provide an appointment to return for further postnatal care, despite all things is going healthy, and provide counseling to coming back instantly if they notice any danger signs [1]. Likewise, if it is home delivery, the first postpartum communication must be as early as possible within 24 hours of birth. Overall, the minimum of three further postpartum checkups is suggested for all mothers and newborns, on day 3 (48-72 hours), between days 7-14 after birth, and 6 weeks after birth [2, 3].

Evidence suggested that the highest proportions of neonatal mortality were found in sub-Saharan Africa and have revealed the sluggish improvement in dropping newborn deaths, particularly deaths in the first week of life. In, African about 1.16 million babies die every year in the first 28 days of life, and 850,000 babies die in the first week of born $[4,5]$.

Based on the Ethiopian national survey data 2016 report, the neonatal mortality rate was $29 \%$ of deaths per 1,000 births [6].

Globally, about 99\% coverage of outreach and institution-based medical care interventions of newborn care can prevent about $41-72 \%$ of neonatal deaths [7].

Therefore, the absence of suitable care during the postpartum period might result in significant ill-health and even demise of newborns [2]. According to a 2016 EDHS report, only $13 \%$ of newborns had received postnatal check in the first two days after birth [6].

Regarding the factors about postnatal checkup of the newborn, different studies showed that antenatal care (ANC) visit during pregnancy, mode of delivery, marital status, wealth index, and distance to the health facility, mother's education, residence, media access, ethnic group, pregnancy desire, and region were a significant predictor of postnatal care (PNC) of a newborn baby [8-13]. Moreover, place of delivery, gravidity, parity, and woman's occupation were determinant factors for PNC services utilization of both the mother and newborn $[14,15]$.

Generally, the first month of the postpartum period is a life-threatening time in the lives of mother and newborn but, it is the most overlooked time for the provision of qualified health care service for the newborn and mother. Therefore, delivering proper postnatal care is life-threatening to safeguard maternal and newborn health $[2,16-18]$. Identifying and intervening thus factors enables postnatal newborn care utilization thereby reducing neonatal mortality. Even though Ethiopia continued to be one the largest sources of maternal and child mortality worldwide, no studies conducted so far to elucidate the factors that perpetuate or hinder postnatal care checkup at the national level. Therefore, this study aimed to identify determinants of postnatal checkup of a newborn in Ethiopia which enables to provide evidence for policy guidelines.

\section{Methods and materials \\ Data}

This study was based on a public domain dataset of 2016 Ethiopian demographic and health survey which is a nationwide representative data. There are a total of 84 , 915 enumerations area (EAs) among them 17,185 are in urban areas and 67,730 in rural areas. The two-stage stratified sampling was employed to collect data. A comprehensive explanations of study design and methods of data collection for the 2016 EDHS is available elsewhere [6]. Data is collected using three main questionnaires which were the men's questionnaire, the household questionnaire, and the women's questionnaire. But, our data was taken from the women's questionnaire which comprises demographic and socioeconomic data on women within their reproductive ages (15-49). All women aged 15-49 years are usual members of the selected households and were eligible for the survey. Afterward rejecting the missing values the total analytic samples of this study were 7091 mothers who have ever given birth in the last five years aged 15-49 years.

\section{Study variables}

The main outcome of interest was the postnatal checkup of newborns. The outcome variable dichotomized as $(0=$ No and $1=$ Yes $)$. The independent variables were carefully chosen from a previous study associated to postnatal checkup of newborn which includes; maternal age, religion, parity, residence, maternal education, media exposure, wealth index, distance to a health facility, mothers occupation, health insurance, antenatal care visit, and place of delivery and size of baby (small, average, and large) [19-25]. Maternal age was recoded as; 15-19, 20-24, 25-34, and 35-49. Likewise, wealth index recoded by merging variables like; (poorest and poorer) as "poor", middle as "middle" and (richer and richest) also merged as "rich". Moreover, media exposure were dichotomized based on answer to how often participants read a newspaper, watched television or, listened to the radio. Respondents who answered at least once a week one of the sources were considered to have accessed to media and recoded as yes $=1$, and otherwise no $=0$. Lastly, mother's occupation was recoded as not working (0) whereas women having different work types as working (1).

\section{Statistical analysis}

The data analysis was done using all necessary statistical procedures. First, descriptive statistics and weighted 
percentages of independent variables were computed. Secondly, Bivariate and multivariate logistic regression analysis was also carried out to examine the association between use of postnatal care of newborn and selected independent variables. Adjusted odds ratios (AOR) were used to state a statistically significant suggestion. The analysis was done using SPSS version 24 [26]. The whole statistical analysis were weighted in order to take into consideration complex survey design, using SPSS.

\section{Result}

\section{Distribution of the characteristics of the study} participants

A total of 7091 samples of reproductive age mothers were involved and analyzed. Out of the samples, $6427(90.6 \%)$ of mothers did not experience postnatal checkup of their newborn whereas the remaining $664(9.4 \%)$ of newborns received postnatal checkup. Among the age category 30-39 years, about 250(35.8\%) of respondents were received postnatal checkups. Similarly, 426(71.8\%) of rural residents were received postnatal checkups at the time of the survey. Regarding the mother's educational status, 286(49.8\%) of them who had no education were received postnatal checkup. Moreover, 408(55.4\%) of the mother who attended 4 and above ANC visits were obtained postnatal checkups.

Besides, bivariate analysis (chi-square test) identified that place of residence, education status of the mother, wealth index, and exposure to mass media, mother occupation, and religion, number of ANC visit, place of delivery, health insurance, and distance to health facility were statistically significantly associated with postnatal care of the newborn baby. (Table 1)

\section{Factors associated with a postnatal checkup of the newborn}

The whole variables were entered into multivariate logistic regression analysis. After adjusting for potential confounders by logistic regression; media access, wealth index, number of ANC visits, and place of delivery were positively associated with the utilization of postnatal checkups. But, being Catholic, Protestant, and Muslim religious followers were negatively associated with the outcome variable.

In this study, the odds of postnatal checkup of the newborn were 1.4 times (AOR: 1.4; 95\% CI: 1.32-1.85) higher among mothers who had access to media than their counterparts. Similarly, the odds of postnatal checkup of the newborn were 1.8 times (AOR: 1.80; 95\% CI: 1.24-2.61) higher among mothers who had rich wealth index status and 1.63 times higher among middle wealth index (AOR: 1.63; 95\% CI: 1.11-2.39) than mother who had poor wealth index.
Regarding religion, the odds postnatal checkup of the newborn were lower by $82 \%$ (AOR: 0.18 ; $95 \%$ CI: $0.42-$ 0.84, 36\% (AOR: 0.66 ; 95\% CI: 0.44-0.99), and 32\% among Catholic, Protestant and Muslim (AOR: 0.68; 95\% CI: 0.49-0.96) religious followers compared than orthodox followers, respectively.

Moreover, the odds of postnatal checkup of the newborn were 2.45 times (AOR: 2.45; 95\% CI: 1.59-3.75) higher among mother who had 1-3 ANC visits and 3.42 times (AOR: 3.42; 95\% CI: 2.16-5.43) higher among mothers who had four and above visits than mother who did not have ANC visit. The odds of postnatal checkups for the newborn were 1.4 times (AOR: 1.4; 95\% CI: 1.32-1.85) higher among mothers who had access to media compared to their counterparts.

Lastly, the odds of postnatal checkups for the newborn were 1.67 times (AOR: 1.67; 95\% CI: 1.18-2.36) higher among mothers who had delivered in a health facilities than those delivered at home. (Table 2)

\section{Discussion}

This study looked at the determinants of postnatal checkup of a newborn in Ethiopia based on data from the 2016 EDHS. In this study, the odds of receiving PNC of the newborn within the 28 days of life were greater among women who had rich and middle wealth classes compared to those mothers who had poor wealth index. This result is reinforced by studies done in India [9], Uganda [27], and Rwanda [13]. The consistency might be for the reason that women who have good wealth status might be autonomous to make a decisions on the use of house hold incomes, and they can also afford payments related to health care service to their newborns and themselves [1,28].

Likewise, this study suggested that access to media by mothers has been found to have a positive association with the use of PNC services among the newborn. This finding is in line with studies done in Uttar Pradesh [29], Uganda [27], and Nigeria [28]. This might be explained by mother's who have access to media have been found to have increased antenatal care visits, which enables them to know the benefits of PNC after birth [1].

Likewise, this study also suggests that newborns whose mothers who had 1-3, and greater than four ANC visits had higher odds of having postnatal checkup of the newborn than those who did not have antenatal care follow up during pregnancy. This finding is in line with studies done in rural Tanzania [15], Uganda [27], Kenya [8], and the Tigray region in Ethiopia [30]. This could be explained that the provision of counseling and health education to mothers by skilled health care providers at the time of ANC follow up is paramount [31]. Moreover, newborns delivered at the health facility were more 
Table 1 Bivariate analysis on determinants of postnatal checkup among the newborn in Ethiopia $(n=7091)$

\begin{tabular}{|c|c|c|c|c|}
\hline \multirow[t]{2}{*}{ Variable } & \multirow[t]{2}{*}{ Category } & \multirow{2}{*}{$\begin{array}{l}\text { Not received PNC }(n=6427) \\
\text { No }(\%)\end{array}$} & \multirow{2}{*}{$\begin{array}{l}\text { Received PNC }(n=664) \\
\text { Yes }(\%)\end{array}$} & \multirow{2}{*}{$\begin{array}{l}\text { Chi-square } \\
p \text {-value }\end{array}$} \\
\hline & & & & \\
\hline \multirow[t]{4}{*}{ Age (in year) } & $15-19$ & $325(4.4)$ & $27(4.6)$ & 0.90 \\
\hline & $20-29$ & $3136(47.7)$ & $327(4.1)$ & \\
\hline & $30-39$ & 2385(37.9) & 250(35.8) & \\
\hline & $40-49$ & $581(9.9)$ & $60(10.2)$ & \\
\hline \multirow[t]{2}{*}{ Residence } & Urban & $1253(11.3)$ & $238(28.2)$ & $<0.001$ \\
\hline & Rural & $5174(88.7)$ & $426(71.8)$ & \\
\hline \multirow[t]{5}{*}{ Religion } & Orthodox & $2004(36.5)$ & $331(4.6)$ & $<0.001$ \\
\hline & Catholic & $47(1.0)$ & $2(0.2)$ & \\
\hline & Protestant & $1217(22.1)$ & 104(18) & \\
\hline & Muslim & $3055(38.1)$ & $220(26.8)$ & \\
\hline & Other & $104(2.2)$ & $7(0.7)$ & \\
\hline \multirow[t]{4}{*}{ Mothers education } & No education & $4005(64.3)$ & 286(49.8) & $<0.001$ \\
\hline & Primary & 1697(28.0) & 219(31.3) & \\
\hline & Secondary & 479(4.9) & $92(12.2)$ & \\
\hline & Higher & $246(67.0)$ & $67(6.6)$ & \\
\hline \multirow[t]{2}{*}{ Occupation } & Not working & $3742(54.5)$ & 283(45.2) & 0.005 \\
\hline & Working & $2685(45.5)$ & $381(54.8)$ & \\
\hline \multirow[t]{3}{*}{ Wealth index } & Poor & $3345(45.4)$ & 209(22.9) & $<0.001$ \\
\hline & Middle & $914(21.0)$ & 97(20.8) & \\
\hline & Rich & 2168(33.6) & $358(56.3)$ & \\
\hline \multirow[t]{2}{*}{ Media access } & No & $4286(67.2)$ & $296(46.0)$ & $<0.001$ \\
\hline & Yes & $2141(32.8)$ & $371(54.0)$ & \\
\hline \multirow[t]{3}{*}{ Number of ANC visit } & None & 2379(39.2) & $66(12.5)$ & $<0.001$ \\
\hline & $1-3$ & 1882(30.9) & 190(32.1) & \\
\hline & $>=4$ & 2166(29.9) & $408(55.4)$ & \\
\hline \multirow[t]{2}{*}{ Place of delivery } & Home & $497(69.3)$ & $229(40.0)$ & $<0.001$ \\
\hline & Health institution & $2330(30.7)$ & $435(60.0)$ & \\
\hline \multirow[t]{3}{*}{ Size of newborn baby } & Small & 1958(32.2) & 202(28.3) & 0.251 \\
\hline & Average & 2675(40.6) & $304(45.1)$ & \\
\hline & Large & 1794(27.2) & 158(26.6) & \\
\hline \multirow[t]{2}{*}{ Distance to the health facility } & Big problem & $3498(59.7)$ & 240(39.4) & $<0.001$ \\
\hline & Not big problem & $2929(40.3)$ & $424(60.6)$ & \\
\hline \multirow[t]{2}{*}{ Health insurance } & No & $6216(96.0)$ & 620(93.1) & 0.013 \\
\hline & Yes & $211(4.0)$ & $44(6.9)$ & \\
\hline
\end{tabular}

likely to receive PNC than those delivered at home which is supported by studies done in rural Uttar Pradesh [29], Nepal [14], Tanzania [15], and Nigeria [32]. This could be justified by mothers delivering at a health facility increases the chances of skilled birth attendance, which plays a vital role in ensuring that mothers and newborns receive comprehensive care, including postnatal care soon after delivery. Another possible explanation for this finding is that delivery at a health facility ensures access to emergency obstetric care to deal with complications during labor, which may also expose women and newborns to postnatal care[27].

Lastly, regarding religion, the odds of postnatal checkups for the newborn among Catholic, Protestant, and Muslim were less likely to utilize newborn care than the orthodox follower. This is finding is supported by a study done in Ethiopia [33] in which being a follower of the orthodox religion associated with postnatal care utilization of mothers and newborns. Even if, we could not find other research to justify, the possible 
Table 2 Multivariate logistic regression showed determinants of postnatal checkup of the newborn in Ethiopia $(n=7091)$

\begin{tabular}{|c|c|c|c|}
\hline Variable & Category & $\operatorname{COR}(95 \% \mathrm{Cl})$ & AOR(95\% Cl) \\
\hline \multirow[t]{4}{*}{ Age } & $15-19$ & 1 & 1 \\
\hline & $20-29$ & $0.98(0.55,1.75)$ & $1.092(0.56-2.10)$ \\
\hline & $30-39$ & $0.90(0.50,1.62)$ & $1.102(0.54-2.24)$ \\
\hline & $40-49$ & $0.98(0.52,1.83)$ & $1.527(0.74-3.15)$ \\
\hline \multirow[t]{2}{*}{ Residence } & Urban & $3.05(2.23,4.24)$ & $1.06(0.64-1.76)$ \\
\hline & Rural & 1 & 1 \\
\hline \multirow[t]{5}{*}{ Religion } & Orthodox & 1 & 1 \\
\hline & Catholic & $0.11(0.02,0.52)$ & $0.18(0.42-0.84)^{*}$ \\
\hline & Protestant & $0.55(0.38,0.79)$ & $0.66(0.44-0.99)^{*}$ \\
\hline & Muslim & $0.47(0.34,0.65)$ & $0.68(0.49-0.96)^{*}$ \\
\hline & Other & $0.20(0.05,0.89)$ & $0.52(0.12-2.14)$ \\
\hline \multirow[t]{4}{*}{ Mothers education } & No education & 1 & 1 \\
\hline & Primary & $1.44(1.08,1.92)$ & $0.92(0.64-1.31)$ \\
\hline & Secondary & $3.21(2.25,4.56)$ & $1.09(0.65-1.83)$ \\
\hline & Higher & $3.16(1.95,5.10)$ & $0.873(0.41-1.87)$ \\
\hline \multirow[t]{2}{*}{ Occupation } & Not working & 1 & 1 \\
\hline & Working & $1.45(1.12,1.88)$ & $1.11(0.84-1.46)$ \\
\hline \multirow[t]{3}{*}{ Wealth index } & Poor & 1 & 1 \\
\hline & Middle & $1.97(1.37,2.81)$ & $1.63(1.11-2.39)^{*}$ \\
\hline & Rich & $3.33(2.48,4.46)$ & $1.80(1.24-2.61)^{*}$ \\
\hline \multirow[t]{2}{*}{ Media access } & No & 1 & 1 \\
\hline & Yes & $2.39(1.85,3.10)$ & $1.4(1.32-1.85)^{*}$ \\
\hline \multirow[t]{3}{*}{ Number of ANC visit } & None & 1 & 1 \\
\hline & $1-3$ & $3.25(2.19,4.83)$ & $2.45(1.59-3.75)^{*}$ \\
\hline & $>=4$ & $5.81(3.98,8.47)$ & $3.42(2.16-5.43)^{*}$ \\
\hline \multirow[t]{2}{*}{ Place of delivery } & Home & 1 & 1 \\
\hline & Health institution & $3.39(2.62,4.41)$ & $1.67(1.18-2.36)^{*}$ \\
\hline \multirow[t]{3}{*}{ Size of a newborn baby } & Small & $0.78(0.59,1.04)$ & $0.82(0.6-1.12)$ \\
\hline & Average & 1 & 1 \\
\hline & Large & $0.88(0.65,1.18)$ & $0.99(0.72-1.35)$ \\
\hline \multirow[t]{2}{*}{ Distance to the health facility } & Big problem & 1 & 1 \\
\hline & Not big problem & $2.27(1.78,2.91)$ & $0.77(0.58-1.02)$ \\
\hline \multirow[t]{2}{*}{ Health insurance } & No & 1 & 1 \\
\hline & Yes & $1.63(0.99,2.67)$ & $0.96(0.53-1.74)$ \\
\hline
\end{tabular}

*show that $p$-value $<0.05$

explanation could be due to differences in religious advice among followers to utilize the postnatal care service of the newborn. Nevertheless, it needs further research to explain the differences in PNC utilization of newborns among followers of different religions.

\section{Conclusions}

This study revealed that accessed media, being rich or middle in the wealth index category, having ANC visits, and institutional delivery was positively associated with the utilization of postnatal checkup of the newborn. The researchers recommended that information education and communication programs should perform a critical role in inspiring mothers to take their newborns for postnatal follow up after birth and great emphasis should be given on ANC service to increase the use of postnatal checkup of the newborn.

\section{Abbreviations}

AOR: Adjusted odds ratio; ANC: Antenatal care; COR: Crude odds ratio; Cl: Confidence interval; EDHS: Ethiopia Demographic Health Science; 
PNC: Postnatal care; SPSS: Statistical Package for Social Science; UNICEF: United Nations International Children's Emergency Fund; WHO: World Health Organization

\section{Acknowledgments}

We would like thankful to the USAID-DHS program for providing access to 2016 Ethiopian.

\section{Authors' contributions}

AS: conceived the research idea, conducted data extraction, data analysis, and data interpretation, wrote, and reviewed the paper. MA: conducted data extraction, reviewed, and approved the final manuscript. The authors have read and approved the manuscript.

\section{Funding}

Not applicable.

\section{Availability of data and materials}

For this analysis, researchers were used the USAID-DHS program 2016 Ethiopian demographic and health survey data set. To request the same or different data for another purpose, a research project should be submitted to the DHS program here; https://dhsprogram.com/data/AccessInstructions. cfmThe DHS Program will normally review all data requests within 24-48 hours and send notification if access has been permitted. Afterward receiving consent, the researcher can login and select the specific data in the format they choose.

\section{Ethics approval and consent to participate}

The data set was gotten from the DHS through registering with the DHS website and as such, no ethical approval was not required.

\section{Competing interests}

The authors declare that they have no competing interests.

\section{Consent for publication}

Not applicable.

\section{Author details}

'Department of Midwifery, College of Health Science, Woldia University, Woldia, Ethiopia. ${ }^{2}$ Department of Public Health, College of Health Science, Woldia University, Woldia, Ethiopia.

\section{Received: 9 June 2020 Accepted: 1 December 2020}

\section{Published online: 07 December 2020}

\section{References}

1. Bwalya BB, Mulenga C. Mulenga, and James N. Mulenga. Factors associated with postnatal care for newborns in Zambia: Analysis of the 2013-14 demographic and health survey. DHS Working Papers. Rockville: ICF International. 2016.

2. World Health Organization. WHO recommendations on postnatal care of the mother and newborn. Geneva: World Health Organization; 2013.

3. WHO. Home visits for the newborn child: a strategy to improve survival Home visits for the newborn child: a strategy to improve survival. Geneva; 2009. Available at: https://www.who.int/maternal_child_adolescent/ documents/who fch cah_09_02/en/.

4. Lawn JE, Cousens S, Zupan J, Team LNSS. 4 million neonatal deaths: when? where? why? Lancet. 2005:365(9462):891-900.

5. Lawn JE, Wilczynska-Ketende K, Cousens SN. Estimating the causes of 4 million neonatal deaths in the year 2000. Int J Epidemiol. 2006:35(3):706-18.

6. ICF. CSACEa. Ethiopia Demographic and Health Survey 2016. Addis Ababa, Ethiopia, and Rockville, Maryland: CSA and ICF.; 2016.

7. Darmstadt GL, Bhutta ZA, Cousens S, Adam T, Walker N, De Bernis L, et al. Evidence-based, cost-effective interventions: how many newborn babies can we save? Lancet. 2005:365(9463):977-88.

8. Akunga D, Menya D, Kabue M. Determinants of postnatal care use in Kenya. Afr Popul Stud. 2014:28(3):1447-59.

9. Singh A, Padmadas SS, Mishra US, Pallikadavath S, Johnson FA, Matthews Z. Socio-economic inequalities in the use of postnatal care in India. PLoS ONE. 2012;7(5):e37037.
10. Amin R, Shah NM, Becker S. Socioeconomic factors differentiating maternal and child health-seeking behavior in rural Bangladesh: A cross-sectional analysis. Int J Equity Health. 2010;9(1):9.

11. Mohan D, Gupta S, LeFevre A, Bazant E, Killewo J, Baqui AH. Determinants of postnatal care use at health facilities in rural Tanzania: multilevel analysis of a household survey. BMC Pregnancy Childbirth. 2015;15(1):282.

12. Somefun OD, Ibisomi L. Determinants of postnatal care non-utilization among women in Nigeria. BMC Res Notes. 2016;9(1):21.

13. Rwabufigiri BN, Mukamurigo J, Thomson DR, Hedt-Gautier BL, Semasaka JPS Factors associated with postnatal care utilisation in Rwanda: A secondary analysis of 2010 Demographic and Health Survey data. BMC Pregnancy Childbirth. 2016;16(1):122.

14. Dhakal S, Chapman GN, Simkhada PP, Van Teijlingen ER, Stephens J, Raja AE. Utilisation of postnatal care among rural women in Nepal. BMC Pregnancy Childbirth. 2007:7(1):19.

15. Kanté AM, Chung CE, Larsen AM, Exavery A, Tani K, Phillips JF. Factors associated with compliance with the recommended frequency of postnatal care services in three rural districts of Tanzania. BMC Pregnancy Childbirth. 2015;15(1):341

16. Sines E, Syed U, Wall S, Worley H. Postnatal care: A critical opportunity to save mothers and newborns. Policy Perspect Newborn Health. 2007;1(7).

17. Martines J, Paul VK, Bhutta ZA, Koblinsky M, Soucat A, Walker N, et al. Neonatal survival: a call for action. The Lancet. 2005;365(9465):1189-97.

18. Baqui AH, Ahmed S, El Arifeen S, Darmstadt GL, Rosecrans AM, Mannan I, et al. Effect of timing of first postnatal care home visit on neonatal mortality in Bangladesh: a observational cohort study. BMJ. 2009;339:b2826.

19. Mageda K, Mmbaga EJ. Prevalence and predictors of institutional delivery among pregnant mothers in Biharamulo district, Tanzania: a cross-sectional study. The Pan African medical journal. 2015;21:51.

20. Tegegne TK, Chojenta C, Loxton D, Smith R, Kibret KT. The impact of geographic access on institutional delivery care use in low and middleincome countries: Systematic review and meta-analysis. PLoS One. 2018; 13(8):e0203130

21. Lean SC, Derricott $H$, Jones RL, Heazell AE. Advanced maternal age and adverse pregnancy outcomes: A systematic review and meta-analysis. PloS one. 2017:12(10):e0186287.

22. Kitui J, Lewis S, Davey G. Factors influencing place of delivery for women in Kenya: an analysis of the Kenya demographic and health survey, 2008/2009. BMC Pregnancy Childbirth. 2013;13(1):40.

23. Huda TM, Chowdhury M, El Arifeen S, Dibley MJ. Individual and community level factors associated with health facility delivery: A cross sectiona multilevel analysis in Bangladesh. PloS one. 2019;14(2):e0211113.

24. Habte F, Demissie M. Magnitude and factors associated with institutional delivery service utilization among childbearing mothers in Cheha district, Gurage zone, SNNPR, Ethiopia: a community based cross sectional study. BMC Pregnancy Childbirth. 2015;15:299.

25. Fekadu GA, Ambaw F, Kidanie SA. Facility delivery and postnatal care services use among mothers who attended four or more antenatal care visits in Ethiopia: further analysis of the 2016 demographic and health survey. BMC Pregnancy Childbirth. 2019;19(1):64

26. Machines IB. IBM SPSS Statistics for Windows, Version 24. Armonk: IBM Corp; 2016

27. Ndugga $P$, Namiyonga NK, Sebuwufu D. Determinants of early postnatal care attendance: analysis of the 2016 Uganda demographic and health survey. BMC Pregnancy Childbirth. 2020:20(1):1-14.

28. Dahiru T, Oche OM. Determinants of antenatal care, institutional delivery and postnatal care services utilization in Nigeria. Pan Afr Med J. 2015;21(321). Available at: https://www.panafrican-med-journal.com/content/article/21/321/full.

29. Varma DS, Khan M, Hazra A. Increasing postnatal care of mothers and newborns including follow-up cord care and thermal care in rural Uttar Pradesh. J Fam Welf. 2010;56(Special Issue):31-41.

30. Abraha TH, Gebrezgiabher BB, Aregawi BG, Belay DS, Tikue LT, Reda EB. Factors Associated with Compliance with the Recommended Frequency of Postnatal Care Services in Four Rural Districts of Tigray Region, North Ethiopia. Kor journal of family medicine. 2019;40(5):329.

31. Sultana N, Shaikh BT. Low utilization of postnatal care: searching the window of opportunity to save mothers and newborns lives in Islamabad capital territory, Pakistan. BMC Res Notes, 2015:8(1):645.

32. Ezeh OK, Agho KE, Dibley MJ, Hall J, Page AN. Determinants of neonatal mortality in Nigeria: evidence from the 2008 demographic and health survey. BMC Publ Health. 2014;14(1):521. 
33. Ayele BG, Woldu MA, Gebrehiwot HW, Gebre-egziabher EG, Gebretnsae H, Hadgu T, et al. Magnitude and determinants for place of postnatal care utilization among mothers who delivered at home in Ethiopia: a multinomial analysis from the 2016 Ethiopian demographic health survey. Reprod Health. 2019;16(1):162.

\section{Publisher's Note}

Springer Nature remains neutral with regard to jurisdictional claims in published maps and institutional affiliations.

Ready to submit your research? Choose BMC and benefit from:

- fast, convenient online submission

- thorough peer review by experienced researchers in your field

- rapid publication on acceptance

- support for research data, including large and complex data types

- gold Open Access which fosters wider collaboration and increased citations

- maximum visibility for your research: over $100 \mathrm{M}$ website views per year

At $\mathrm{BMC}$, research is always in progress.

Learn more biomedcentral.com/submissions 